Perhaps more significantly, however, it was the formulation of geological concepts, the laws of superposition and principle of uniformitarianism, which in the end led to ideas of duration of processes and hence to a relative time scale. Professor Kirkaldy stresses the importance of the early workers in these fields and goes on to demonstrate how the next step, of correlating strata by their included fossils, came about. Thus, with these fundamental principles, workers were able to erect stratigraphic successions and, in doing so, make relative datings of beds. The added complications of breaks and modifications (for example, unconformities and orogenies) in the succession are explained and their significance in working out a time sequence is demonstrated.

Following on from this, Professor Kirkaldy surveys the methods by which estimates of elapsed time have been drawn up. Thickness of sediments and rates of sedimentation as methods, salinity increases, palaeontology and evolutionary rates, and the rate of cooling of the Earth are discussed at length. All give markedly different ages to the same rocks.

After this survey of relative methods of age determination the book continues with an introduction to dating using radioactive isotopes. This is an exceedingly useful chapter, the physical concepts behind the determination being clearly set out and each of the principal isotope ratio methods explained. The specific advantages of each method are given together with the rocks, or more properly minerals, on which it is best used.

In 1913 Arthur Homes was one of the first to draw up an absolute time scale from data available. Scales were modified as new dates became available and as more precise techniques for isotope measurement were invented. In this part of the book the more problematical determinations of Pleistocene and Recent dates are examined and the reliability of dates throughout the stratigraphic column is pointed out. Methods of determining time sequences in metamorphic and highly folded and faults areas are indicated, and this has a bearing on the account of Precambrian time which follows. The book ends with a discussion of the age of the Earth and the solar system, and the significance that Moon dates have on this.

This is certainly a book which all beginners in geology should read, and it will provide a valuable refresher course to their more experienced colleagues. If isotope measurements are to be used it is important that geologists understand how they are calculated and how reliable the dates derived are, unless he is to accept them blindly.

$$
\text { J. R. V. BRoOKs }
$$

\section{Soil Analysis}

A Textbook of Soil Chemical Analysis. By P. R. Hesse. Pp. xxiii +520 . (John Murray: London, April 1971.) £7.50.

This book is designed to provide a course on soil chemical analysis and will prove to be a valuable text both for teachers and students. Practising soil chemists should also find much of interest in it. The two introductory chapters, covering the purpose of soil analysis, precision and accuracy, preparation of samples and the interpretation of results, are excellent; the author's critical awareness of the problems involved should help to dispel "the myth of soil analysis being the answer to the farmer's problem". The remaining sixteen chapters are given to a particular element, group of elements, or property of soil, and cover most chemical topics of interest to a soil scientist. The chapter on waterlogged soils is an innovation that should stimulate work on an important but neglected subject.

Most chapters have a short introduction, rather more extensive for lesser known topics, then a section on the background and theory of the determination, and finally practical details for recommended methods. A number of different approaches are described for most problems, covering the literature fairly thoroughly, and making the book a more comprehensive guide than has been available hitherto.

The analytical methods for which detailed instructions are given use chiefly simple apparatus so that they are well within the scope of the average soil laboratory; this should particularly commend the book for situations where resources are limited. Sophisticated instrumental methods are mentioned where they can make a contribution, but the reader is referred to other publications for details. Simple diagrams of apparatus, and flow sheets for some of the complex determinations, are welcome aids to clarity. Appendices contain references, bibliography and useful information on standard solutions, conversion factors and so on, and there is a full subject index.

Analysis of soil is a very different proposition from conventional chemical analysis, for the total amount of an element or compound is only rarely required. The need, rather, is for the proportion that is likely to be involved in the process under study, be it pedogenesis or plant nutrition. An essential prerequisite for effective procedures is thus an understanding of basic soil chemistry, and it is gratifying that one of the prime aims of this text is "to narrow the gap between the theory of soil chemistry and the manuals of soil analysis". That this gap still seems to be rather wide in some cases is due not only to the complexity of soil chemistry, but also to the uneven treatment given here to the underlying theory, particularly the more physicochemical aspects. There are also a number of misleading statements that undermine the book's authority on general soil chemistry. The author is clearly on safer ground when dealing with analytical procedures.

Rapid advances in this important practical subject will ensure that a second edition is required eventually. This should provide the opportunity to remedy some blemishes in an otherwise excellent publication. B. W. BACHE

\section{Analysis of Sediments}

Procedures in Sedimentary Petrology. Edited by Robert E. Carver. Pp. xiii + 653. (Wiley: New York and London, June 1971.) $£ 11.75$.

This book is intended as a guide to the standard procedures for measurement and analysis of sediments. There are six principal sections which deal with the analysis of sedimentary structuressize, grain, texture, mineralogy and chemistry. Several authors contribute chapters to these sections and the coverage of subject matter is fairly complete. There are chapters on thin section making, heavy mineral separation, staining, point counting, peels and impressions, X-ray photography, X-ray diffraction, porosity and so forth.

Size analysis is well covered with a useful table of sieve data, sieve analysis, pipette analysis and related methods of sedimentation analysis (including the rapid sediment analyser using a water pressure transducer). Instrumentation for electronic grain size measurements in thin sections is described and a mathematical treatment of size distribution is followed by an examination of grain size shapes and grain surface textures. Scanning electron microscopy is used to identify the effects of littoral, aeolian and glacial environments on the surfaces of grains. The sections on mineralogical analyses give a good account of gravity separation, but magnetic and electromagnetic methods are not adequately described, nor is any reference made to the "micropanner" which is often a useful tool.

The chapters on X-ray photography are particularly interesting and more use should be made of it in petrology. The chief difficulty is the general lack of suitable medical/industrial-type X-ray units in most geological departments, although excellent X-radiographs of rocks can be obtained from a small apparatus employing a ${ }^{125}$ I source (Weiss, Amer. Assoc. Petrol. Geol., 50, 1507 : 1966). There is a thorough treatment of optimum sample thickness and other parameters, together with descriptions of the more special techniques of stereo X-radiography which is of considerable value in studies of three- 